\title{
Pressure Mapping and Hemodynamic Assessment of Intracranial Dural Sinuses and Dural Arteriovenous Fistulas with 4D Flow MRI
}

\author{
(D).A. Rivera-Rivera, (DK.M. Johnson, (DP.A. Turski, and (D). Wieben
}

O- $\equiv$

\begin{abstract}
SUMMARY: The feasibility of 4D flow MR imaging to visualize flow patterns and generate relative pressure maps in the dural venous sinus in healthy subjects $(n=60)$ and patients with dural arteriovenous fistulas $(n=7)$ was investigated. Dural venous drainage was classified based on torcular Herophili anatomy by using 4D flow MR imaging-derived angiograms and magnitude images. Subjects were scanned in a $3 T$ clinical MR imaging system. 4D flow MR imaging enabled noninvasive characterization of dural sinus anatomy and mapping of relative pressure differences.
\end{abstract}

ABBREVIATIONS: DAVF $=$ dural arteriovenous fistula; $\mathrm{TS}=$ transverse sinus

$V_{\mathrm{r}}$ enous hypertension is thought to be implicated in dural arteriovenous fistulas (DAVFs) with aggressive presentation. ${ }^{1,2}$ We investigated the use of 4D flow MR imaging for the noninvasive assessment of $\mathrm{DAVFs}^{3}$ through measuring the vascular velocity vector field. These data can be processed for the analysis of the spatial and temporal distributions of flow and pressure gradients, ${ }^{4-6}$ including dural venous sinus pressure and flow patterns. The purpose of this study was to compare $4 \mathrm{D}$ flow MR imagingderived hemodynamics and relative pressure maps in the dural venous drainage of patients with DAVF and healthy subjects. In addition, we report on the anatomic variations found in the dural venous drainage.

Received July 7, 2017; accepted after revision October 26.

From the Departments of Medical Physics (L.A.R.-R., K.M.J., P.A.T., O.W.) and Radiology (K.M.J., P.A.T., O.W.), University of Wisconsin School of Medicine and Public Health, Madison, Wisconsin.

This work was supported by National Institute on Aging grant P50-AG033514, National Institute of Neurological Disorders and Stroke grant R01NS066982, National Heart, Lung, and Blood Institute grant R01HL072260, National Institute of General Medical Sciences grant R25GM083252, the American Society of Neuroradiology Alzheimer's Grant Award, and GE Healthcare.

Paper previously presented at: Annual Meeting and Exhibition of the International Society for Magnetic Resonance in Medicine, April 22-27, 2017; Honolulu, Hawaii, and Annual Meeting of the American Society of Neuroradiology, April 22-27, 2017; Long Beach, California.

Please address correspondence to Oliver Wieben, PhD, University of WisconsinMadison, Room 1127, Wisconsin Institutes for Medical Research, 1111 Highland Ave, Madison, WI 53705-2275; e-mail: owieben@wisc.edu

- Indicates open access to non-subscribers at www.ajnr.org

三 Indicates article with supplemental on-line tables.

$\square$ Indicates article with supplemental on-line photos.

http://dx.doi.org/10.3174/ajnr.A5494

\section{MATERIALS AND METHODS}

Seven patients (age range, 33-72 years; mean age, 52 years; 2 women) diagnosed with unilateral DAVFs affecting the transverse/sigmoid sinus and 60 healthy subjects (age range, 45-75 years; mean age, 64 years; 32 women) were scanned by using a 3T clinical MR imaging system (MR750; GE Healthcare, Milwaukee, Wisconsin) with an 8-channel head coil. Phase-contrast MR imaging data with 3-directional velocity encoding were acquired with a radially undersampled $4 \mathrm{D}$ flow MR imaging sequence, phase contrast with vastly undersampled isotropic projection (PC-VIPR), ${ }^{7,8}$ and the following imaging parameters: velocity encoding $=80 \mathrm{~cm} / \mathrm{s}$ for control patients (TR, $7.4 \mathrm{~ms}$; TE, $2.7 \mathrm{~ms}$ ) and $100 \mathrm{~cm} / \mathrm{s}$ for patients with DAVFs (TR, $7.8 \mathrm{~ms}$; TE, $2.5 \mathrm{~ms}$ ); FOV $=22 \times 22 \times 16 \mathrm{~cm}^{3} ; 0.7 \mathrm{~mm}$ isotropic resolution; 14,000 projection angles; scan time $=\sim 7$ minutes; flip angle $\alpha=10^{\circ}$; and receiver bandwidth $= \pm 83 \mathrm{kHz}$. Magnitude, velocity data, and PC angiograms were all generated with off-line reconstruction. Background phase correction of velocities was performed in Matlab (MathWorks, Natick, Massachusetts), and vessel segmentation was performed semiautomatically (Mimics; Materialise, Leuven, Belgium) from the phase-contrast angiograms. Pressure maps were also calculated in Matlab by using previously validated methods. ${ }^{5,6}$ This approach solves the Navier-Stokes equation by assuming blood is an incompressible Newtonian fluid (density $=1060 \mathrm{~kg} / \mathrm{m}^{3}$; viscosity $=3.2 \mathrm{cP}$ ). Visualization of pressure differences and flow quantification were carried out in EnSight (CEI, Apex, North Carolina). Flow and area were quantified from cut planes in each transverse sinus (TS), left and right, placed $25 \mathrm{~mm}$ from the torcular Herophili, and pressure gradients were quantified as the pressure difference at $25 \mathrm{~mm}$ and $50 \mathrm{~mm}$ from the torcular Herophili. These measurements were per- 
formed by a Ph.D. candidate with 5 years of MR imaging postprocessing experience (L.A.R.-R.). The anatomy of the dural sinuses was classified according to Gökçe et $\mathrm{al}^{9}$ based on torcular Herophili anatomy. A senior neuroradiologist (P.A.T., $>30$ years of experience) inspected the images to determine anatomic classification.

Statistics were assessed by using ANOVA followed by post hoc analysis with the Tukey-Kramer method. Data normality was assessed with quantile-quantile plots. Analysis was performed in Matlab. $P<.05$ was set as the threshold for statistical significance.

\section{RESULTS}

Representative color pressure maps in a healthy subject and a patient with DAVF are shown in Fig 1. For the healthy subject (Fig $1 A,-D)$, blood pressure decreased downstream with lower pressure in the TS than in the superior sagittal sinus. However, the

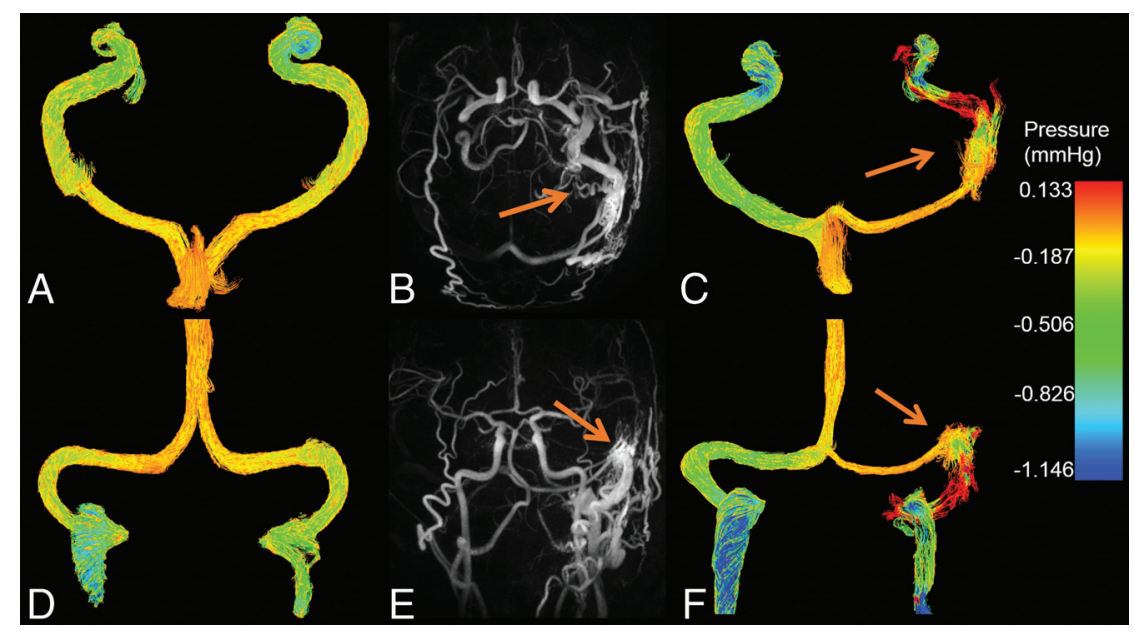

FIG 1. Color pressure maps $(\mathrm{mm} \mathrm{Hg})$ in a healthy subject in the axial $(A)$ and coronal $(D)$ planes as well as for a patient ( $C$ and $F$ ) with a type lla DAVF affecting the left transverse and sigmoid sinus (arrows). MIP images in the axial $(B)$ and coronal $(E)$ plane show the site of arteriovenous shunting (arrows) where there is increased pressure seen on the axial $(C)$ and coronal $(F)$ pressure maps. patient with DAVF (Fig 1C, -F) shows a pressure increase in the TS affected by the fistula and a decrease on the TS contralateral to the DAVF. Another patient pressure map and flow streamlines can be found in On-line Figs 1 and 2. The streamlines move retrograde from the site affected by the fistula into the right TS.

The anatomic variations in the dural sinus drainage were catalogued as follows: for healthy subjects, there were 10 type I, 35 type II, and 15 type III variations (On-line Fig 3 and On-line Table 1). For patients with DAVF, there were 5 type I and 2 type II variations. Flow and cross-sectional area measurements in healthy subjects are summarized in On-line Table 2.

Flow and pressure drops in the TS for all subjects are shown in Fig 2. For patients with DAVF, pressure increased along the TS ipsilateral to the fistula with a median of $0.055 \pm 0.130 \mathrm{~mm} \mathrm{Hg}$, whereas pressure decreased in the TS contralateral to the fistula with a median of $-0.367 \pm 0.205 \mathrm{~mm} \mathrm{Hg}(P=.109)$. In healthy subjects, the pressure decreased very similarly in both TSs, with values of $-0.105 \pm 0.033 \mathrm{~mm} \mathrm{Hg}$ and $-0.101 \pm 0.043 \mathrm{~mm} \mathrm{Hg}$, respectively $(P=.994)$. In patients with DAVF, flow in the TS affected by the fistula was $40 \pm$ $129 \mathrm{~mL} / \mathrm{min}$, and flow in the TS contralateral to the fistula was $328 \pm 134$ $\mathrm{mL} / \mathrm{min}(P=.046)$. In healthy subjects, independent of anatomy type, flow was significantly larger in the right TS $(262 \pm 83 \mathrm{~mL} / \mathrm{min})$ compared with the left TS $(121 \pm 56 \mathrm{~mL} / \mathrm{min} ; P<.001)$.

\section{DISCUSSION}

Initially, we characterized dural venous sinus pressure in a population of 60 healthy subjects, establishing a reference frame for the interpretation of dural sinus pathology. The main findings of this study are an increase in pressure in the TS ipsilateral to the DAVF compared
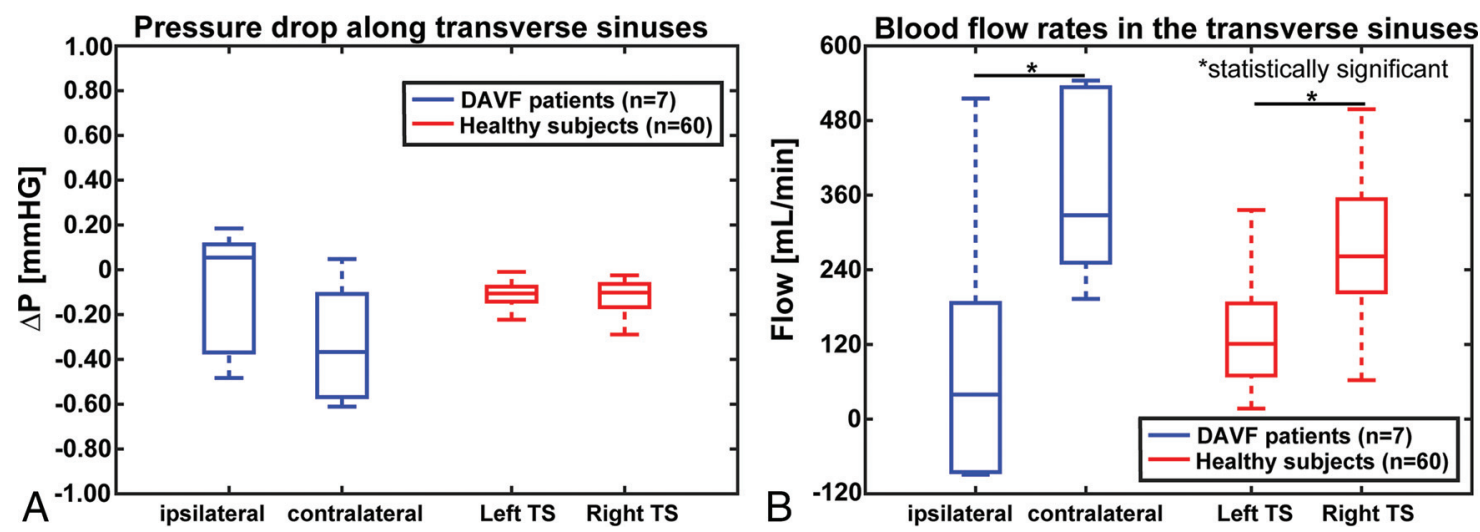

FIG 2. Boxplots showing the pressure change $(A)$ and blood flow rates $(B)$ along the TS in the patients with DAVF $(n=7)$ and healthy subjects $(n=$ 60). The pressure drops were computed from the difference in pressure in 2 cut planes placed on each TS. The cut planes were placed $25 \mathrm{~mm}$ and $50 \mathrm{~mm}$ from the torcular Herophili. The median pressure drop in the ipsilateral and contralateral TS to the DAVF were $0.055 \pm 0.130 \mathrm{~mm} \mathrm{Hg}$ and $-0.367 \pm 0.205 \mathrm{~mm} \mathrm{Hg}$, respectively $(P=.109)$. In the healthy subjects, the pressure drops were $-0.105 \pm 0.033 \mathrm{~mm} \mathrm{Hg}$ in the left TS and $-0.101 \pm 0.043 \mathrm{~mm} \mathrm{Hg}$ in the right TS $(P=.994)$. The median blood flow rates in the patients with DAVF show a value of $40 \pm 129 \mathrm{~mL} / \mathrm{min}$ in the TS affected by the fistula and, in the TS contralateral to the fistula, equal to $328 \pm 134 \mathrm{~mL} / \mathrm{min}(P=.046)$. The median flow in healthy subjects including all anatomy types was significantly larger in the right TS compared with the left TS, with values of $262 \pm 83 \mathrm{~mL} / \mathrm{min}$ and $121 \pm 56$ $\mathrm{mL} / \mathrm{min}$, respectively $(P<.001)$. 
with a pressure drop in the contralateral TS. In healthy subjects, the pressure dropped similarly in the left and right TS. These findings suggest asymmetric pressure drops can potentially be used to identify patients with DAVFs, in whom the TS displaying an increase in pressure or smaller pressure drop represents the site affected by the DAVF. During conventional angiography, dural sinus pressure gradients are frequently measured invasively by navigating a coaxial microcatheter to the draining dural sinus. This preliminary study demonstrates that it is feasible to characterize relative pressure in DAVFs noninvasively by using $4 \mathrm{D}$ flow MR imaging.

Retrograde dural/cortical venous drainage is a risk factor for intracranial hemorrhage in patients with DAVFs. ${ }^{1}$ Consequently, hemodynamic assessment of DAVFs is important for an accurate characterization of severity. Blood flow directionality was successfully assessed for both patients with DAVF and healthy subjects. During this study, 1 patient DAVF classification was changed. Initially, the fistula was classified as type I; after demonstrating retrograde flow in the $4 \mathrm{D}$ flow MR imaging, the fistula was reclassified as Type IIa in the Cognard system. The technique described in this study can be implemented to explore other pathologies such as venous stenosis, which is often associated with idiopathic intracranial hypertension and pulsatile tinnitus. ${ }^{10}$

There are a number of limitations in this study. First, for group comparisons, we used time-average data because cardiac data were not recorded for all but 1 patient with DAVF. Second, the MR imaging technique we used has some potential inaccuracies in pressure mapping in the presence of turbulent flow, which requires more advanced pressure solvers. ${ }^{11}$ The pressure maps have not been validated against a criterion standard, which will be addressed in a follow-up study with invasive conventional angiography measures that navigate a coaxial microcatheter to the draining dural sinus. This study will also contain more patients with DAVFs.

\section{CONCLUSIONS}

Noninvasive pressure mapping in the dural sinuses is feasible with 4D flow MR imaging. In addition, 4D flow MR imaging allows blood flow directionality assessment along the dural sinuses, which can help clinicians detect retrograde flow in DAVFs.

\section{ACKNOWLEDGMENTS}

One of the main contributors to this publication, Zachary J. Clark, $\mathrm{MD}$, passed away suddenly and tragically before this manuscript was completed. Due to ICJME (international committee of medical journal editors) authorship requirements that all authors have the opportunity to review revisions and proofs prior to publication, Dr. Clark could not be included in the authors list. Zach greatly contributed to this work and will be dearly missed.

Disclosures: Kevin M. Johnson-RELATED: Grants/Grants Pending: National Institutes of Health*; UNRELATED: Consultancy: Vertex Pharmaceuticals; Other: GE Healthcare, Comments: the University of Wisconsin-Madison receives research support from GE Healthcare*. Patrick A. Turski-RELATED: Grants/Grants Pending: National Institutes of Health, Comments: RO1 Accelerated Neurovascular MRA*. Oliver Wieben—UNRELATED: Other: GE Healthcare, Comments: research agreement*. *Money paid to the institution.

\section{REFERENCES}

1. Gandhi D, Chen J, Pearl M, et al. Intracranial dural arteriovenous fistulas: classification, imaging findings, and treatment. AJNR Am J Neuroradiol 2012;33:1007-13 CrossRef Medline

2. Bernstein RA, Gress DR. Dural arteriovenous fistulas and the neurology of venous hypertension. Semin Cerebrovasc Dis Stroke 2004;4: 168-75 CrossRef

3. Markl M, Frydrychowicz A, Kozerke S, et al. 4D flow MRI. J Magn Reson Imaging 2012;36:1015-36 CrossRef Medline

4. Tyszka JM, Laidlaw DH, Asa JW, et al. Three-dimensional, timeresolved (4D) relative pressure mapping using magnetic resonance imaging. J Magn Reson Imaging 2000;12:321-29 CrossRef Medline

5. Moftakhar R, Aagaard-Kienitz B, Johnson K, et al. Noninvasive measurement of intra-aneurysmal pressure and flow pattern using phase contrast with vastly undersampled isotropic projection imaging. AJNR Am J Neuroradiol 2007;28:1710-14 CrossRef Medline

6. Bley TA, Johnson KM, François CJ, et al. Noninvasive assessment of transstenotic pressure gradients in porcine renal artery stenoses by using vastly undersampled phase-contrast MR angiography. Radiology 2011;261:266-73 CrossRef Medline

7. Gu T, Korosec FR, Block WF, et al. PC VIPR: a high-speed 3D phasecontrast method for flow quantification and high-resolution angiography. AJNR Am J Neuroradiol 2005;26:743-49 Medline

8. Johnson KM, Lum DP, Turski PA, et al. Improved 3D phase contrast MRI with off-resonance corrected dual echo VIPR. Magn Reson Med 2008;60:1329-36 CrossRef Medline

9. Gökçe E, Pınarbaşılı T, Acu B, et al. Torcular Herophili classification and evaluation of dural venous sinus variations using digital subtraction angiography and magnetic resonance venographies. Surg Radiol Anat 2014;36:527-36 CrossRef Medline

10. Lansley JA, Tucker W, Eriksen MR, et al. Sigmoid sinus diverticulum, dehiscence, and venous sinus stenosis: potential causes of pulsatile tinnitus in patients with idiopathic intracranial hypertension? AJNR Am J Neuroradiol 2017;38:1783-88 CrossRef Medline

11. Ha H, Lantz J, Ziegler M, et al. Estimating the irreversible pressure drop across a stenosis by quantifying turbulence production using 4D flow MRI. Sci Rep 2017;7:46618 CrossRef Medline 